\title{
An Approach To Predict Coronavirus Disease (Covid-19) In India Using Arima Model
}

\author{
Swati Hira \\ ${ }^{1}$ Assistant Professor, Shri Ramdeobaba College of \\ Engineering and Management, Nagpur India
}

\section{ABSTRACT}

Novel coronavirus (COVID-19) is started from Wuhan (City in China) and is rapidly spreading among people living in other countries. Today around 215 countries are affected by COVID-19 disease. WHO announced approximately number of confirmed cases are 30.4 worldwide including 943,433 deaths. In India as of 18 September 2020 total number of confirmed cases $5.31 \mathrm{M}$. To more efficiently manage this spread, there is an immediate need to track and forecast the prevalence of COVID-19. Analysis of time series models is an effective way to predict this COVID-19 outbreak and take the appropriate action to react to this epidemic. The ARIMA models were developed in this study to predict the COVID19 epidemiological trend of Maharashtra, Tami Nadu, Andhra Pradesh, Karnataka, and Uttar Pradesh in India. The data of COVID-19 is collected for period of 12 March 2020 to 10 September 2020 WHO. Various ARIMA time-series models were created with different parameters. After analysis ARIMA $(1,2,0)$ is chosen as an appropriate model for COVID-19 prevalence. The findings of the study will reveal insight into understanding the pattern of the epidemic and also provide an understanding of the epidemiological phases of these states. In addition Maharashtra, Tami Nadu, Andhra Pradesh, Karnataka, and Uttar Pradesh analysis of COVID-19 prevalence pattern will help to take precautions and formulate strategies for this epidemic.

\section{INTRODUCTION}

In December 2019 the novel coronavirus disease (COVID19) originated as a new species which is not previously found in humans. New COVID-19 virus increases the serious pneumonia infections and has spread widely from Wuhan City, across China, and now to more than 215 countries. Now it is becoming a worldwide serious public health issue. This infection causes deadly impacts, particularly on the older and those with ceaseless ailments .The disease spread quickly and has a complex structure.

\section{ARTICLE INFORMATION}

Received 19th Oct 2020 Accepted after revision 22nd Dec 2020 Print ISSN: 0974-6455 Online ISSN: 2321-4007 CODEN: BBRCBA

Thomson Reuters ISI Web of Science Clarivate Analytics USA and Crossref Indexed Journal

\section{Clarivate
Analytics}

NAAS Journal Score 2020 (4.31)

A Society of Science and Nature Publication,

Bhopal India 2020. All rights reserved.

Online Contents Available at: http//www.bbrc.in/

Doi: $h$ ttp://dx.doi.org/10.21786/bbrc/13.14/77
Due to variations in detection capacities and epidemiological surveillance cases vary between states, but as of now this disease has spread worldwide. Since for this category of virus no treatment available yet, there is an urgent need of healthcare services, which helps to control the spreading of this virus. Mathematical modelling tools are available to estimates the cases and to plan the amount of additional resources and necessary services was expected to tackle this epidemic. It is important for healthcare systems to predict the projected burden of illness to coordinate medical treatment related services required to provide outbreak solution. Now a days, numerous statistical and mathematical methods in use to analyse COVID-19 cases. For example multivariate linear regression, time series models, grey forecasting models, simulation models, and back propagation neural networks. Various indicators affect this epidemic spread. Because of this, Tendencies and randomness mark the general distribution of the outbreak. Hence, the statistical methods listed are inadequate to examine the randomness, of the outbreak and the generalization of these models are complex.

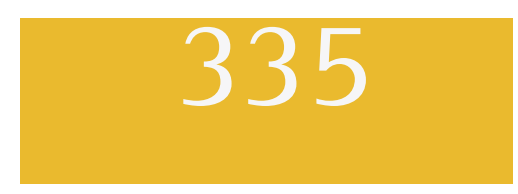


The ARIMA statistical model is used by several health care systems and also in other areas because of its easy to use and data description feature. This models also deployed successfully to predict various infectious diseases as influenza fatality and malaria prevalence hepatitis. In addition, ARIMA models are extensively used to analyse time series of epidemic diseases for example haemorrhagic and dengue fever, and tuberculosis. ARIMA models used to demonstrate time series dependency structure, their varying trends, seasonal variations and randomness. So it is easy to describe to people and also motivate us to make use of this method in decision making process. In current studies various models were applied to predict COVID- 19 disease incidence and prevalence.

For example, researcher has developed a mathematical function to estimate and analyse the current trend of outbreak corona virus in China. Authors created and evaluated this outbreak to forecast cumulative confirmed cases. Researcher describe the temporal characteristic of this pandemic in countries like China, Italy, and France. Author has compared the two standard frameworks as SIR and SEIR to estimate the COVID-19 in Wuhan city. The national and global transmission of COVID-19 to estimate its impact on the different regions of Wuhan and its nearby area is analyzed by author. Author provide the improved system based on Fuzzy techniques names as ANFIS and applied Swarm Intelligence technique for confirmed cases identification. One more algorithm is created by author for estimation of COVID patient death rate in real time.
So we can say that, various studies are available in the previous work to analyse and estimate the COVID19 transmission in China. However, United States has become the virus epicenter and affect the US continent more than China. As of September 18, 2020, 85,650 deaths recorded in India. Therefore, it is momentous to predict the COVID-19 situation prevalence pattern, in the top 5 corona infected states in India. The objective of our study is to estimate the COVID-19 prevalence of Indian states: Maharashtra, Tami Nadu, Andhra Pradesh, Karnataka, Uttar Pradesh, where the virus is spreading with high rate and causing disastrous results. The time period between 12 March 2020 and 10 September 2020 is considered for analysis purpose and analysed using various ARIMA models. These predictive models will help to predict future need of healthcare systems and additional resources for the patients in various countries.

\section{METHODS}

2.1 Data selection: The COVID-19 prevalence data is collected from the WHO website Python programming is used to perform statistical test. Table 1 shows the complete statistical description of the COVID-19 data for top 5 effected states in India between 12 March 2020 to 10 September 2020. This study makes use of a time series having 182 days to estimate COVID-19 prevalence in 5 states as Maharashtra, Tami Nadu, Andhra Pradesh, Karnataka, and Uttar Pradesh over the coming 2 months.

Table 1. Statistics summary of COVID-19 in Maharashtra, Tami Nadu, Andhra Pradesh, Karnataka, Uttar Pradesh

\begin{tabular}{|l|l|l|l|c|c|c|c|c|c|}
\hline States & Average: & $\begin{array}{c}\text { Standard } \\
\text { Deviation: }\end{array}$ & Skew: & $\begin{array}{c}\text { Excess } \\
\text { Kurtosis: }\end{array}$ & Median: & Minimum: & Maximum: & $\begin{array}{c}\text { 1st } \\
\text { Quartile: }\end{array}$ \\
\hline Quartile: \\
\hline $\begin{array}{l}\text { Prevalence } \\
\text { Andhra }\end{array}$ & & & & & & & \\
Pradesh & 83835.32 & 144691 & 1.72 & 1.65 & 5269 & 1 & 527512 & 1137 & 92484.5 \\
\hline Maharashtra & 219885 & 267357.8 & 1.19 & 0.25 & 94041 & 11 & 967349 & 7848 & 371083.5 \\
\hline $\begin{array}{l}\text { Tamil } \\
\text { Naidu }\end{array}$ & 117605.1 & 147473 & 1.09 & -0.21 & 36841 & 1 & 480524 & 1853 & 210230 \\
\hline Karnataka & 69414.34 & 114208.6 & 1.67 & 1.58 & 6041 & 4 & 421730 & 506 & 93541.5 \\
\hline $\begin{array}{l}\text { Uttar } \\
\text { Pradesh }\end{array}$ & 50542.32 & 75478.56 & 1.64 & 1.53 & 11610 & 11 & 285041 & 1899 & 65365 \\
\hline $\begin{array}{l}\text { Incidence } \\
\text { Andhra }\end{array}$ & 793.0109 & 1302.322 & 1.67 & 1.46 & 78 & 0 & 4634 & 31 \\
\hline $\begin{array}{l}\text { Pradesh } \\
\text { Maharashtra }\end{array}$ & 7633.262 & 8504.851 & 0.89 & -0.55 & 3438 & 0 & 27787 & 332.5 & 13522.5 \\
\hline $\begin{array}{l}\text { Tamil } \\
\text { Naidu }\end{array}$ & 1873.596 & 2530.583 & 1.18 & -0.05 & 326 & 0 & 8090 & 23.5 & 3451.5 \\
\hline Karnataka & 1200.667 & 1918.598 & 1.54 & 1.06 & 69 & 0 & 6808 & 19 \\
\hline $\begin{array}{l}\text { Uttar } \\
\text { Pradesh }\end{array}$ & 892.7978 & 1143.933 & 1.33 & 0.62 & 321 & 0 & 4112 & 30 \\
\hline
\end{tabular}


From Figure. 1, we can observe that the COVID-19 outbreak confirmed cases in Maharashtra are highest in number than other states. As per the records Maharashtra reported 11 COVID-19 cases on 12 March 2020. In Maharashtra, the count of confirmed cases of COVID-19 is 40238946 . The south western located city Mumbai was most affected. The neighboring regions of Mumbai as Navi Mumbai, Pune and Nagpur is also effected by COVID 19 badly. The overall prevalence of COVID-19 in India shown in Fig1. The hardest-hit state in Maharashtra. Tamil Nadu and Andhra Pradesh are the second and third badly affected states in India. Confirmed cases on 12-032020 in Andhra Pradesh and Tamil Nadu was 1 which was less as compared to other states. Now both south states are at 2 and 3rd position in Maharashtra and total confirmed cases jumped to 15341864 and 21521742.

2.2. ARIMA models: A time series is explained with the timely ordered data points. Temporal analysis objective is to report accurate and important statistics information to estimate time series future data values. This ARIMA model was introduced in 1970s by author Box and Jenkins. The ARIMA time series models is most commonly used as it consider changing pattern, seasonal changes and random time series disturbance. This time series model is applicable in different kinds of data, including pattern, cyclic and seasonality.
Figure 1: COVID-19 prevalence and incidence in Maharashtra, Tami Nadu, Andhra Pradesh, Karnataka, Uttar Pradesh.

\section{Daily confirmed COVID-19 cases}
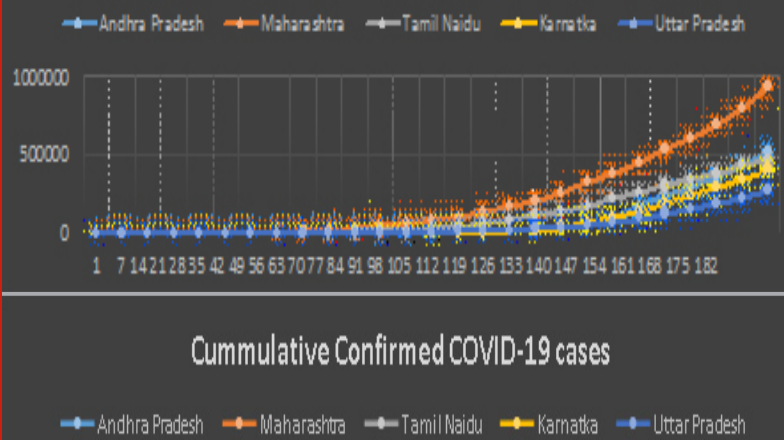

60000000

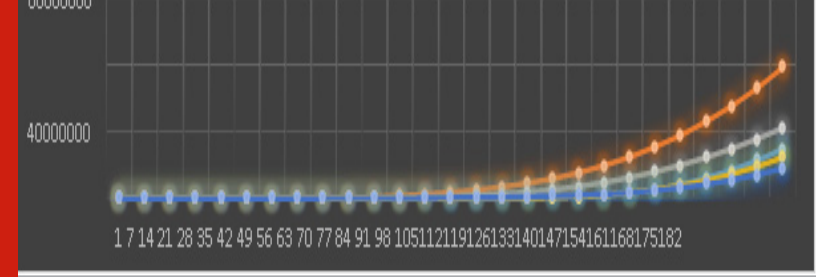

Table 2. Parameter estimation of different ARIMA models

\begin{tabular}{|c|c|c|c|c|c|c|c|}
\hline State & Best Model & Parameter & Coefficient & STD Error & LLC & P-stat & z-stat \\
\hline \multirow[t]{4}{*}{ Andhra Pradesh } & $\operatorname{ARIMA}(1,2,0)$ & $\mathrm{AR}(1)$ & -0.1559 & 0.073 & -1423 & 0.033 & -2.128 \\
\hline & $\operatorname{ARIMA}(0,2,1)$ & MA(1) & -0.2564 & 0.098 & -1421 & 0.009 & -2.621 \\
\hline & \multirow{2}{*}{ ARIMA $(1,2,1)$} & $\mathrm{AR}(1)$ & 0.3692 & 0.134 & -1419 & 0.006 & 2.762 \\
\hline & & MA(1) & -0.6170 & 0.102 & & 0.000 & -6.027 \\
\hline \multirow[t]{4}{*}{ Maharashtara } & ARIMA(1,2,0) & $\mathrm{AR}(1)$ & -0.2011 & 0.074 & -1535.757 & 0.007 & -2.709 \\
\hline & $\operatorname{ARIMA}(0,2,1)$ & MA(1) & -0.5517 & 0.087 & -1529.294 & 0.000 & -6.310 \\
\hline & \multirow[t]{2}{*}{ ARIMA $(1,2,1)$} & $\mathrm{AR}(1)$ & 0.3177 & 0.103 & -1524.593 & 0.002 & 3.099 \\
\hline & & MA(1) & -0.7336 & 0.064 & & 0.000 & -11.464 \\
\hline \multirow[t]{4}{*}{ TamilNadu } & $\operatorname{ARIMA}(1,2,0)$ & $\mathrm{AR}(1)$ & 0.1634 & 0.073 & -1201.054 & 0.026 & 2.231 \\
\hline & $\operatorname{ARIMA}(0,2,1)$ & MA(1) & 0.1938 & 0.080 & -1200.627 & 0.015 & 2.436 \\
\hline & \multirow[t]{2}{*}{ ARIMA $(1,2,1)$} & $\mathrm{AR}(1)$ & -0.8273 & 0.043 & -1196.644 & 0.000 & -19.109 \\
\hline & & MA(1) & 1.0000 & 0.027 & & 0.000 & 37.395 \\
\hline Karnataka & $\operatorname{ARIMA}(1,2,0)$ & $\mathrm{AR}(1)$ & -0.1941 & 0.074 & -1426.851 & 0.009 & -2.623 \\
\hline Uttar Pradesh & ARIMA(1,2,0) & $\mathrm{AR}(1)$ & -0.4084 & 0.068 & -1287.220 & 0.000 & -6.048 \\
\hline
\end{tabular}

It is versatile and can also be applied to model time series temporal dependency nature. ARIMA model is described as an ARIMA $(p, d, q)$ where $p$ indicates the order of auto regression, $d$ indicates the degree of difference, and $q$ indicates the order of moving average.

\section{RESULTS AND DISCUSSION}

3.1. COVID-19 prevalence forecasting by applying ARIMA model: The basic four iterative steps involved in ARIMA model are: model assessment, parameters estimation, symptomatic evaluation, and prediction. The model categorize the time series as stationary and seasonal. Stationary nature shows constant behavior over time i.e. mean, variance, and autocorrelation which helps to retrieve accurate results. The seasonality and stationarity of a time series can be observed with Time series plot, Autocorrelation Function (ACF), and Partial Autocorrelation Function (PACF) graphs. Beside the best ARIMA models, other models were also constructed, and compared to observe their performances. In order to pick ARIMA models as the best models, statistically relevant parameters were chosen and the ARIMA $(1,2,0)$ models is selected which fitted the COVID-19 data fairly well (Table 2). The associated p-values of used parameters 
are less than 0.05 , which indicates the significance of selected model. The fitted and predicted values are presented in Fig. 3.

Figure 3: Time-series plots for the best ARIMA models

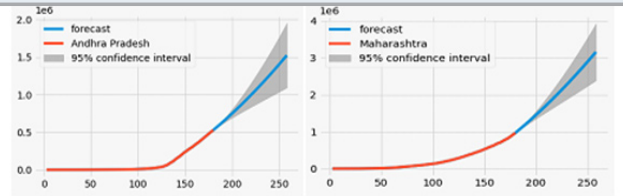

(a)

(b)

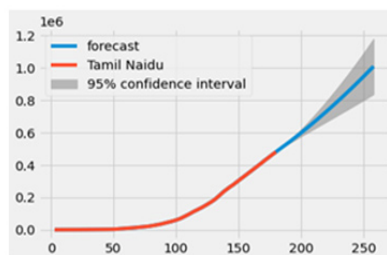

(c)

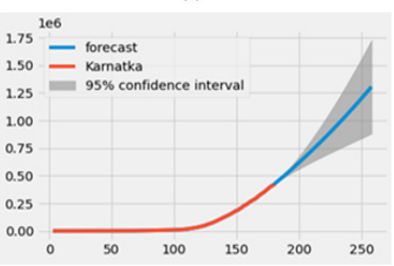

(d)

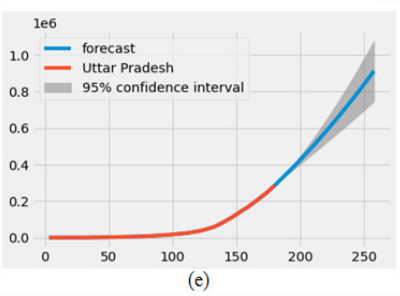

DISCUSSION

In order to prevent and monitor the spread of epidemics, successful strategies are required. The COVID-19 time series trend must be calculated for the allocation of medical services, to improve production and also to start and increase the import/export activity among countries. Hence an effective forecasting model needs to be established that can benefit governments in decision making during emergency situation and facilitate the required medical resources.

Because of its simplicity and systematic structure, and reasonable forecasting efficiency, ARIMA model is one of the most widely used time series forecasting models. The work performed in this paper discussed about the recent COVID-19 situation in 5 Indian states as Maharashtra, Tami Nadu, Andhra Pradesh, Karnataka, Uttar Pradesh. The ability of our Indian health system to appropriately and immediately satisfy the infected patient's basic health requirements is of great concern. Especially in Maharashtra, the infected patients trend increases exponentially since 12 March and no decreasing trend of new cases is observed and the plateau seems to take more days to hit. This trend would result in intensive care units being at their highest capacities. Otherwise, psychological and social issues would be unmanageable and result as disaster.

\section{CONCLUSION}

It is necessary for health departments to forecast Disease incidence with a view to developing monitoring programmers Resources and reallocate them. Disease prediction using ARIMA models play an important role. In this analysis, models of the ARIMA time series were applied to the overall COVID-19 prevalence of five Indian states affected by COVID- 19: Maharashtra, Tami Nadu, Andhra Pradesh, Karnataka, and Uttar Pradesh in India. The results of this work will help politicians and health care policies to offer good plan and resources to cope with the crisis over the world in the coming days and weeks, including nurses, beds and intensive care facilities. The data should be modified in real time to allow for more accurate comparison and future perspectives.

\section{REFERENCES}

Fanelli, D., Piazza, F., 2020. Analysis and forecast of COVID-19 spreading in China, Italy and France. Chaos, Solitons and Fractals 134, 1-12. https://doi. org/10.1016/j. chaos.2020.109761.

He, Z., Tao, H., 2018. International Journal of Infectious Diseases Epidemiology and ARIMA model of positiverate of in fl uenza viruses among children in Wuhan, China: a nineyear retrospective study. Int. J. Infect. Dis. 74, 61-70. https://doi.org/10.1016/j.ijid.2018.07.003.

Kurbalija, V., Ivanovi, M., Schmidt, D., Lindemann, G., Trzebiatowski, V., Burkhard, H., Hinrichs, C., 2014. Time-series analysis in the medical domain: a study of Tacrolimus administration and influence on kidney graft function. Comput. Biol. Med. 50, 19-31. https:// doi.org/10.1016/j.compbiomed.2014.04.007.

Li, Q., Feng, W., Quan, Y.H., 2020. Trend and forecasting of the COVID-19 outbreak in China. J. Inf. Secur. 80, 469-496. https://doi.org/10.1016/j.jinf.2020.02.014 Li, Q., Feng, W., Quan, Y.H., 2020. Trend and forecasting of the COVID-19 outbreak in China. J. Inf. Secur. 80, 469-496. https://doi.org/10.1016/j.jinf.2020.02.014

Roosa, K., Lee, Y., Luo, R., Kirpich, A., Rothenberg, R., Hyman, J.M., Yan, P., Chowell, G., 2020. Real-time forecasts of the COVID-19 epidemic in China from February 5th to February 24th, 2020. Infect. Dis. Model. 5, 256-263.https://doi.org/10.1016/j.idm.2020.02.002 Roda, W.C., Varughese, M.B., Han, D., Li, M.Y., 2020. Why is it difficult to accurately predict the COVID-19 epidemic? Infect. Dis. Model. 5, 271- 2

Thomson, M.C., Molesworth, A.M., Djingarey, M.H., Yameogo, K.R., Belanger, F., Cuevas, L.E., 2006. Potential of environmental models to predict meningitis epidemics in Africa. Trop. Med. Int. Heal. 11, 781-788. https://doi.org/10.1111/j.1365-3156.2006.01630.x

Wang, L., Li, J., Guo, S., Xie, N., Yao, L., Day, S.W., Howard, S.C., Graff, J.C., Gu, T., 2020. J. ur of. Sci. Total Environ., 138394 https://doi.org/10.1016/j. scitotenv.2020.138394.

Zhang, S., Diao, M., Yu, W., Pei, L., Lin, Z., Chen, D., 2020. International Journal of Infectious Diseases Estimation of the reproductive number of novel coronavirus (COVID-19) and the probable outbreak size on the Diamond Princess cruise ship: a data-driven analysis. Int. J. Infect. Dis. 93, 201-204. https://doi. org/10.1016/j.ijid.2020.02.033 